\title{
Facile one-step electrodeposition preparation of poly(L-Ornithine) film modified glassy carbon electrodes for sensitive detection of Thiamethoxam
}

Chi Zhang ( $\square$ zhangchi211@zzu.edu.cn )

The First Affiliated Hospital of Zhengzhou University

Yulong Zhang

Gaiping Li

Lina Zou

\section{Research Article}

Keywords: Thiamethoxam, L-Ornithine, Electropolymerization, Voltammetric sensor

Posted Date: March 3rd, 2022

DOI: https://doi.org/10.21203/rs.3.rs-1379859/v1

License: (c) (1) This work is licensed under a Creative Commons Attribution 4.0 International License. Read Full License 


\section{Abstract}

In this work, a green, low-cost and environmental-friendly voltammetric sensor, poly(L-Ornithine) film modified glassy carbon electrode was fabricated for the first time and used for determination of pesticide thiamethoxam. The modified electrode was characterized by cyclic voltammetry and electrochemical impedance spectroscopy. The redox character of thiamethoxam at proposed sensor was studied systematically. Utilizing the linear sweep voltammetry, a wider linear range $\left(5.0 \times 10^{-8} \mathrm{~mol} \mathrm{~L}^{-1}-9.0 \times 10^{-6}\right.$ mol L-1) and lower detection limit $\left(1.7 \times 10^{-8} \mathrm{~mol} \mathrm{~L}^{-1}\right)(\mathrm{S} / \mathrm{N}=3)$ for the detection of thiamethoxam were achieved. In addition, the proposed method was successfully applied to the determination of thiamethoxam in the real sample with satisfactory results.

\section{Introduction}

Pesticides are wildly used to increase the production of grains, fruits and vegetables that are vulnerable to pests. ${ }^{[1]}$ However, some pesticides are endocrine disrupting compounds. ${ }^{[2]}$ Thiamethoxam, [(EN)-3-(2chloro-1,3-thia-zol-5-ylmethyl)-5-methyl-1,3,5-oxadiazinan-4-ylidene(nitro)-amine] (Scheme. 1(a)), belongs to the second generation of neonicotinoid insecticide and has been widely used in the world due to its merits, such as lower toxicity and high activity against pests and insects. ${ }^{[3]}$ It is one of the most used neonicotinoid insecticides and is amongst the most profitable pesticides used for foliar, soil and seed treatment. ${ }^{[4]}$ Owing to its high solubility in water systems, it may threaten environmental safety and human health. ${ }^{[5]}$ Therefore, rapid and sensitive determination of thiamethoxam in environment samples is necessary. Up to now, there are some methods for the determination of thiamethoxam reported, such as high-performance liquid chromatography (HPLC), ${ }^{[6]}$ liquid chromatography-electros-pray mass spectrometry (LC-EMS), ${ }^{[7]}$ enzyme-linked immunosorbent assay (ELISA), ${ }^{[8]}$ electrochemical sensing analysis. Among these technologies, electrochemical sensor has unique advantages, such as simplicity, high sensitivity, rapid response and low cost.

In order to improve the performance for the detection of thiamethoxam, chemical modification is often employed in electrochemical sensor. A variety of nanomaterials were used for their large specific surface area, good conductivity and catalytic performance, including metal nanoparticles ${ }^{[9]}$, carbon nanomaterials ${ }^{[10]}$, cyclodextrin ${ }^{[11]}$ and calixarene ${ }^{[12]}$. And the most commonly used modification method is direct drop coating for its simple, fast and easy to operate. However, there are some things that deserve improvement. Sometimes, the electrode modification materials are too complex to synthesize and toxic to the environment. Although the drop coating is simple, but this method has poor controllability, which has adverse effect on the stability and reproducibility of the sensor. Therefore, it is necessary to develop an environmentally friendly, convenient, good stability and sensitive electroanalytical method for determination of thiamethoxam.

As we all know, conducting polymer has attracted considerable interest and employed in the electrochemical sensor, ion recognition and electron transfer. ${ }^{[13-15]}$ Among them, amino acid as material 
to build sensing interface for analytical application was reported, ${ }^{[16,17]}$ which reveals that amino acids are promising materials for electrochemical sensors. L-Ornithine ((2S)-2, 5-Diaminopentanoi-c acid) (Scheme. 1(b)), one of alkaline amino acids, ${ }^{[18]}$ is non-protein amino acid with various functions which has been widely applied in many areas, such as in physiological functions, medical treatment, health care and chemical industry. Most importantly, it is less harmful to the environment. Up to now, there has no report about L-Ornithine applied to electrode modified material. So, it has potential research value. In the preparation method of polymer film modified electrode, electrochemical polymerization has its unique advantages. Compared with drip coating, it is not only easy to operate, but also has higher controllability. Because the parameters of electrochemical polymerization, such as potential, time and substrate solution, can be precisely controlled. So, the prepared electrode has good stability and reproducibility. This is helpful to improve the performance of the sensor and promote its practical application. For LOrnithine, an amino acid soluble in water, its electropolymerization substrate does not need to use organic solution, which is also conducive to environmental protection.

Hereby, in this work, L-Ornithine was firstly used as a green electrode modification material for fabricating electropolymerization L-Ornithine modified glassy carbon electrode (poly(L-Ornithine)/GCE). As a new voltammetric sensor, it was used for determination of thiamethoxam with high sensitivity and wider detection linear range. The electrochemical properties of thiamethoxam were investigated systematically and the dynamic parameters of electrode process were obtained by a series of electrochemical measurement. In addition, the reduction reaction mechanism of thiamethoxam was speculated reasonably.

\section{Experimental}

\subsection{Apparatus and reagents}

Electrochemical measurements were performed on a RST3000 electrochemical system (Risetceh Instrument Company, Suzhou, China). A three-electrode system was used, consisting of a bare or modified GCE (3 mm diameter) working electrode, a saturated calomel electrode (SCE) and a platinum (Pt) wire counter electrode. All the $\mathrm{pH}$ values were measured with a $\mathrm{PHS}-3 \mathrm{C}$ precision $\mathrm{pH}$ meter (Jingke Devices Factory of Shanghai, China). All the water used in this work was obtained from a Thermo Scientific Barnstead GenPure water purification system (Thermo Fisher Scientific Co., Ltd ,Shanghai, China) with electrical resistance $\geq 18.2 \mathrm{M} \Omega \cdot \mathrm{cm}$.

L-Ornithine ( $\geq 98 \%$ ) was purchased from Shanghai Yuanye Bio-Technology Co., Ltd (Shanghai, China). Thiamethoxam ( $\geq 98 \%$ ) were procured from the Aladdin (Shanghai, China). The stock solution of Thiamethoxam $\left(1 \times 10^{-2} \mathrm{~mol} \mathrm{~L}^{-1}\right)$ was prepared with ultra-pure water and kept in darkness at $4^{\circ} \mathrm{C}$. The real sample of Thiamethoxam was procured from local drugstore (Zhengzhou, China). Working solutions were prepared daily by diluting the stock solution of Thiamethoxam with $0.1 \mathrm{~mol} \mathrm{~L}^{-1}$ Phosphate buffer solution (PBS), which were prepared by mixing the stock solutions of $0.1 \mathrm{~mol} \mathrm{~L}^{-1} \mathrm{NaH}_{2} \mathrm{PO}_{4}$ and 
$\mathrm{Na}_{2} \mathrm{HPO}_{4}$. The lower $\mathrm{pH}$ was adjusted with $0.1 \mathrm{~mol} \mathrm{~L}^{-1} \mathrm{H}_{3} \mathrm{PO}_{4}$. All other reagents were of analytical grade and were used directly without further purification. All experiments were performed at room temperature.

\subsection{Fabrication of the poly(L-Ornithine) modified glassy carbon electrodes}

Prior to modification, the bare GCE was polished to a mirror with $0.3 \mu \mathrm{m}$ alumina slurry, and then sonicated in ethanol and water successively. Firstly, the modified electrode was prepared by cyclic scanning between $-1.5 \mathrm{~V}$ and $+2.5 \mathrm{~V}$ at $0.1 \mathrm{~V} \mathrm{~s}^{-1}$ for 3 cycles in PBS 8.0 containing $2.5 \times 10^{-3} \mathrm{~mol} \mathrm{~L}^{-1}$ L-Ornithine. The obtained modified electrode was marked as PLO/GCE. Next, the PLO/GCE was dried naturally and used for following experiments.

\subsection{Analytical measurement process}

For getting stable voltammograms, the prepared PLO/GCE was scanned between penitential of $-0.5 \mathrm{~V}$ and $-1.2 \mathrm{~V}$ with rate of $0.1 \mathrm{~V} \mathrm{~s}^{-1}$ in PBS 8.0 for 3 cycles. When the cyclic voltammogram was steady, a certain volume of thiamethoxam standard solution was added into the electrochemical cell. Then, the cyclic voltammetry (CV) or linear sweep voltammetry (LSV) was performed. The renewal of PLO/GCE was easily achieved in $0.05 \mathrm{~mol} \mathrm{~L}^{-1} \mathrm{NaOH}$ solution by successive sweeping of two cycles between $-0.5 \mathrm{~V}$ and $-1.2 \mathrm{~V}$ to give a regenerated electrode surface. For investigating the analytical method, LSV was employed for establishing calibration curve.

\section{Results And Discussion}

\subsection{Electrochemical polymerization mechanism and conditions}

Cyclic voltammograms of L-Ornithine under repetitive sweeping of 10 cycles were shown in Fig. 1. In the first cycle, three weak anodic peaks (marked P1, P2 and P3) at $+0.1 \mathrm{~V}, 1.02 \mathrm{~V}$ and $+1.5 \mathrm{~V}$ and a large cathodic peak (P4) at $-0.701 \mathrm{~V}$ was observed in turn. In subsequent cycles, these four peaks increased concurrently, suggesting that the amount of electroactive polymer increased on GCE surface. At the same time, it was also observed that the peak current increased faster in the initial five cycles than that in the later five cycles. From the sixth cycle, the peak current increased more slowly. After electropolymerization, a uniform and greenish blue film of poly(L-Ornithine) could be seen by bare eyes on the GCE surface. Under the high potential conditions, amino acids could be oxidized for free amino groups and then form carbon-nitrogen bond on the surface of the bare electrode, the electrochemical polymerization mechanism was shown in Scheme. 2.

For a polymer modified electrode, its electrochemical response for the analyte was greatly affected by the polymeric conditions: the electro-polymeric film thickness and the $\mathrm{pH}$ of polymeric solution. The cyclic number of polymerization was studied in the range of one to five cycles. In the solution of thiamethoxam 
$\left(1.0 \times 10^{-5} \mathrm{~mol} \mathrm{~L}^{-1}\right)$, the response current of thiamethoxam was gradually increased from one to three cycles number of PLO/GCE, which might be attributed to the fact that the reaction sites increased along with the cyclic number. So, the electrochemical response of thiamethoxam increased accordingly. Then, the peak current decreased when the cyclic number exceeded four. This might owe to the charge was hindered with the incrassation of the polymer film. Therefore, three cycles were used in the following experiments. Moreover, the value of the polymeric solution $\mathrm{pH}$ was also investigated and the largest peak current of thiamethoxam was obtained in PBS 8.0 of the polymeric solution.

\subsection{Infrared Spectra of PLO/GCE}

Figure 2. showed the IR spectra of L-Ornithine (curve a) and poly(L-Ornithine) (curve b). The wide absorption peak between $3333.89 \mathrm{~cm}^{-1}$ and $3419.11 \mathrm{~cm}^{-1}$ in the L-Ornithine spectrum corresponding to the $\mathrm{N}-\mathrm{H}$ bond of $-\mathrm{NH}_{2}$ and $\mathrm{O}-\mathrm{H}$ stretching vibration in the $-\mathrm{COOH}$. An absorption peaks at $1678 \mathrm{~cm}^{-1}$, were ascribed to the stretching vibrations of $\mathrm{C}=\mathrm{O}$ in Amino acids. In addition, the absorption peaks at 1538 $\mathrm{cm}^{-1}$ and $1215 \mathrm{~cm}^{-1}$ were ascribed to the stretching vibration of $\mathrm{C}-\mathrm{N}$ and the bending vibration of $\mathrm{N}-\mathrm{H}$. However, the obvious decrease of characteristic absorption peaks at 3333.89 in the poly(L-Ornithine) spectrum, the significantly reduced of $-\mathrm{NH}_{2}$ in the polymer film, which is consistent with the polymerization mechanism of amino acids. Moreover, an absorption peaks at $1635.24 \mathrm{~cm}^{-1}$ was correspond to the the stretching vibrations of $\mathrm{C}=\mathrm{O}$ of Poly(Amino-acids). The results of infrared spectroscopy revealed that poly(L-Ornithine) composite was synthesized on the glassy carbon electrode.

\subsection{The electrochemical characterization of PLO/GCE}

To obtain more information about the PLO/GCE, $\mathrm{Fe}(\mathrm{CN})_{6}{ }^{3-/ 4-}$ was employed as an electrochemical probe for characterising the electrode surface with cyclic voltammetry (CV). As shown in Fig. 3A, a pair of welldefined redox peak was observed at the bare GCE (curve a) with $i_{\mathrm{pa}}=-12.93 \mu \mathrm{A}$ and $i_{\mathrm{pc}}=12.17 \mu \mathrm{A}$. When the bare GCE was covered with a layer of poly(L-Ornithine) (curve b), the current of $\mathrm{K}_{3} \mathrm{Fe}(\mathrm{CN})_{6}$ was increased slightly $\left(i_{\text {pa }}^{\prime \prime}=-13.79 \mu \mathrm{A}, i_{\text {pc }}^{\prime \prime}=17.17 \mu \mathrm{A}, \Delta \mathrm{E}_{\mathrm{p}}=71 \mathrm{mV}\right)$. Because the $-\mathrm{NH}_{2}$ was introduced on the GCE surface after polymerization of L-Ornithine. There will be electrostatic attraction between $-\mathrm{NH}_{2}$ and $\mathrm{Fe}\left[(\mathrm{CN})_{6}\right]^{3-}$. EIS is an important technique for clarifying the electrode surface. Nyquist plots of bare GCE (curve a) and PLO/GCE (curve b) were recorded in $5 \times 10^{-3} \mathrm{~mol} \mathrm{~L}^{-1} \mathrm{Fe}\left[(\mathrm{CN})_{6}\right]^{3-/ 4-}$ containing $0.1 \mathrm{~mol}$ $\mathrm{L}^{-1} \mathrm{KCl}$ as supporting electrolyte (Fig. $3 \mathrm{~B}$ ). The semicircle obtained at higher frequency (on the Nyquist plot) corresponded to the electron-transfer limited process, and its diameter is equal to the electron transfer resistance $\left(R_{c t}\right)$. The values of $R_{c t}$ were $93.89 \Omega$ for bare GCE and $26.31 \Omega$ for PLO/GCE. These results indicated that a faster interfacial electron transfer took place at the PLO/GCE, this characteristic would make the modified electrode have better response performance.

\subsection{Electrochemical response of Thiamethoxam at PLO/GCE}


Figure 4 presented the cyclic voltammograms of thiamethoxam $\left(5.0 \times 10^{-5} \mathrm{~mol} \mathrm{~L}^{-1}\right.$ ) at bare GCE (curve b) and PLO/GCE (curve d). Curves a and $\mathrm{c}$ were the voltammograms in blank solution. It can be obtained from Fig. 4. that no redox peak was observed in the blank solution (curve a, curve c). After addition of thiamethoxam in the blank solution, a very weak cathodic peak appeared at bare electrode (curve b). When the PLO/GCE was used, the cathodic peak current was increased greatly (curve d), which can be attributed to the electrocatalytic property of poly(L-Ornithine) toward thiamethoxam.

\subsection{Influence of $\mathrm{pH}$ and scan rate}

As we all known, the voltammetric response of electro-active substance was affected by the supporting electrolyte and solution $\mathrm{pH}$. Changing the solution $\mathrm{pH}$ could be used to detect the $\mathrm{H}^{+}$number taking part in the electrode reaction. The voltammetric response of thiamethoxam in different supporting electrolytes were investigated, such as PBS, B-R, Tris and Abs. The results showed that higher peak current and better peak shape was obtained in PBS, which was adopted to use for the following experiments.

Then, the influence of solution $\mathrm{pH}$ on the voltammetric response of thiamethoxam $\left(5.0 \times 10^{-5} \mathrm{~mol} \mathrm{~L}^{-1}\right)$ was investigated in the range of $\mathrm{pH}$ from 2.0 to 8.0. As shown in Fig. 5A, the cathodic peak currents changed gradually and the peak potentials were negatively shifted by increasing the solution $\mathrm{pH}$ values. This indicated that there was proton taking part in the electrode reaction of thiamethoxam. In terms of peak shape and current response, pH 7.0 of PBS was chosen as the supporting electrolyte in the following studies. In addition, the relation between solution $\mathrm{pH}$ and peak potential $\left(\mathrm{E}_{\mathrm{p}}\right)$ was linearly obeyed the following equation: $E_{p}(V)=-0.0267 p H-0.8644(R=0.9933)$ (Fig. 5B). According to the Nernst equation, this slope of $-0.0267 \mathrm{~V} / \mathrm{pH}$ suggested that the ratio of the proton and electron transfer number was $1: 2$.

To further elucidate the electrode reaction character, cyclic voltammetry with different scan rates was performed in a $5.0 \times 10^{-5} \mathrm{~mol} \mathrm{~L}^{-1}$ thiamethoxam solution. Figure $6 \mathrm{~A}$ was the superimposed voltammograms with scan rates from $30 \mathrm{mV} \mathrm{s}^{-1}$ to $300 \mathrm{mV} \mathrm{s}^{-1}$. With increasing scan rate, the peak current grew and peak potential shifted negatively. Moreover, a good linear relationship was obtained between $\log i_{\mathrm{p}}$ and $\log v$ (Fig. 6B) with correlation equation of $\log i_{\mathrm{p}}=0.6383 \log v-0.8690,(\mathrm{R}=0.9994$, $\left.i_{\mathrm{p}}: \mu \mathrm{A}, v . \mathrm{mV} \mathrm{s}^{-1}\right)$. This result demonstrated the electrode reaction of thiamethoxam controlled by both adsorption and diffusion. ${ }^{[16]}$ According to Laviron's theory, the $E_{p}-v$ relation could be described as following equation: ${ }^{[19]}$

$$
E_{p}(V)=E^{\bullet}-\frac{R T}{\alpha n F} \ln \frac{R T k_{s}}{\alpha n F}+\frac{R T}{\alpha n F} \ln v
$$

where $\mathrm{E}^{\Phi}$ is the formal potential; $\mathrm{n}$ is the transfer electron number; $a$ refers to charge transfer coefficient; $\mathrm{F}$ is the Faraday constant and $k_{\mathrm{s}}$ is the apparent rate constant. $\mathrm{R}$ and $\mathrm{T}$ have their usual meaning. 
In addition, the variation of $E_{p}$ with In $v$ was represented as shown in Fig. $6 \mathrm{C}$ with a regression equation of $E_{p}(m V)=-31.59 \ln v\left(m ~ s^{-1}\right)-895.05, R=0.9986$. From the slope of $E_{p}$ against In $v$ straight line, an $=$ 0.81 could be obtained and the $n$ value could be calculated to be 2 (a was assumed to be 0.5 firstly). In turn, the charge transfer coefficient a was also estimated to be 0.41 . Therefore, two electrons were involved in the electrochemical reduction process of thiamethoxam. Considering the above results, the proton number taking part in the electrode reaction was 1 and a possible reduction reaction mechanism of thiamethoxam was shown in Scheme 3.

\section{Scheme 3}

\subsection{Chronocoulometry studies}

As mentioned above, the electrode reaction of thiamethoxam was controlled by both adsorption and diffusion. It was necessary to calculate its saturating adsorption capacity and diffusion coefficient at the sensor surface. Chronocoulometry was the best technique for doing this work. For this system, PLO/GCE was immersed in a $1.0 \times 10^{-5} \mathrm{~mol} \mathrm{~L}^{-1}$ thiamethoxam for several minutes to achieve the saturated adsorption. Next, a potential step from $-0.5 \mathrm{~V}$ to $-1.2 \mathrm{~V}$ was applied (Fig. 7A, curve b). For contrast, $\mathrm{Q} \sim \mathrm{t}$ curve was also recorded in blank PBS solution (Fig. 7A, curve a). The corresponding $Q \sim t^{1 / 2}$ curves were obtained and displayed in Fig. 7B. The linear equations of $Q \sim t^{1 / 2}$ were $Q\left(10^{-5} C\right)=2.8501 t^{1 / 2}+2.3946$ $(R=0.9996)$ and $Q\left(10^{-5} C\right)=5.5831 t^{1 / 2}+21.4738(R=0.9999)$ for the curve $a^{\prime}$ and $b^{\prime}$. From above result, the curves in a' and ' $b^{\prime}$ had the different slope values, which demonstrated again that the electrode reaction of thiamethoxam was controlled by adsorption along with diffusion. According to the formula given by Anson: [20]

$Q_{\text {total }}=\frac{2 n F A c(D t)^{1 / 2}}{\pi^{1 / 2}}+Q_{d l}+Q_{a d s}$

Here, $A$ is the area of electrode, $D$ is the diffusion coefficient of the species, $\mathrm{C}$ is the bulk concentration of the species, $t$ is the potential pulse width, $Q_{d l}$ is double-layer charge, $Q_{a d s}$ is the Faradaic charge due to the reduction of adsorbed thiamethoxam. Other symbols have their usual meanings. Here, $Q_{a d s}$ is the intercept difference of curves a' and 'b', and its value was calculated to be $1.9079 \times 10^{-4} \mathrm{C}$. Using Laviron's theory of $\mathrm{Q}=\mathrm{nFA} \Gamma^{*} .{ }^{[21]}$ The saturating adsorption capacity $\left(\Gamma^{*}\right)$ was calculated as $1.3990 \times 10^{-}$ $8 \mathrm{~mol} \mathrm{~cm}^{-2}$. Meanwhile, the diffusion coefficient (D) was calculated according to the slope of curve $b^{\prime}$ and a value of $1.3160 \times 10^{-7} \mathrm{~cm}^{2} \mathrm{~s}^{-1}$ was obtained.

\subsection{Analytical applications and method validation 3.7.1. Influence of accumulation time}

In consideration of the detection sensitivity and adsorption of thiamethoxam on the PLO/GCE surface, the effect of accumulation time ( $\left.t_{\mathrm{acc}}\right)$ on the peak current was studied. This experiment was performed in $1.0 \times 10^{-5} \mathrm{~mol} \mathrm{~L}^{-1}$ thiamethoxam solution with $\mathrm{CV}$ technique. Results showed that the peak current of 
thiamethoxam changed gradually with increasing $t_{a c c}$ from $30 s$ to $210 s$ and the maximum peak current was obtained at $90 \mathrm{~s}$. As far as we know, a longer $t_{a c c}$ can result in higher detection sensitivity, but can also lead to narrow detection linear range. For comprehensive consideration of detection sensitivity and linear range, $90 \mathrm{~s}$ was used to establish the calibration curve of thiamethoxam. Therefore, the $t_{\mathrm{acc}}$ of $90 \mathrm{~s}$ was carried out under an open circuit for further studies.

\subsubsection{Calibration curve and detection limit}

Under optimum conditions, the relationship between peak currents and thiamethoxam concentrations was investigated using linear sweep voltammetry (LSV) technique. Figure 8A showed the superimposed LSV curves of different thiamethoxam concentrations. From experiment result, the peak currents of thiamethoxam were increased with the increasing thiamethoxam concentrations. And a good linear relationship was obtained between the peak current $\left(i_{p}\right)$ and thiamethoxam concentrations in the range of $5.0 \times 10^{-8}-9.0 \times 10^{-6} \mathrm{~mol} \mathrm{~L}^{-1}$ (Fig. 8B). The linear regression equation was $i_{\mathrm{p}}\left(10^{-6} \mathrm{~A}\right)=5.6791 \mathrm{C}(\mu \mathrm{mol} \mathrm{L}$ $\left.{ }^{1}\right)+4.3356(R=0.9990)$ with detection limit of $1.7 \times 10^{-8} \mathrm{~mol} \mathrm{~L}^{-1}(\mathrm{~S} / \mathrm{N}=3)$. By comparison of the different voltammetric sensors for the determination of thiamethoxam (Table 1), it can be seen that a simple and sensitive method was achieved using the proposed sensor. Moreover, comparing with other sensors, the voltammetric sensors was more convenient, simple, and environmentally friendly.

Table 1

Comparison of different electrochemical sensors for determination of thiamethoxam.

\begin{tabular}{|llll|}
\hline Sensors & $\begin{array}{l}\text { Analytical range } \\
\left(\mathrm{mol} \mathrm{L}^{-1}\right)\end{array}$ & $\begin{array}{l}\text { Detection limit } \\
\left(\mathrm{mol} \mathrm{L}^{-1}\right)\end{array}$ & \begin{tabular}{l} 
Ref. \\
\hline Ag-CPE
\end{tabular} \\
\hline Co304@g-C3N4/SPCE & $1.0 \times 10^{-4} \sim 1.0 \times 10^{-3}$ & $3.6 \times 10^{-5}$ & 9 \\
\hline Cyclodextrin/rGO/GCE & $5.0 \times 10^{-8} \sim 4.2 \times 10^{-4} \sim 1.6 \times 10^{-5}$ & $4.9 \times 10^{-9}$ & 10 \\
\hline Silver electrode & $1.0 \times 10^{-5} \sim 1.0 \times 10^{-4}$ & $5.5 \times 10^{-6}$ & 11 \\
\hline BC-DM/GCE & $1.7 \times 10^{-6} \sim 1.2 \times 10^{-4}$ & $7.5 \times 10^{-7}$ & 23 \\
\hline Thiamethoxam-MIP/Au/rGO/SPCE & $0.5 \times 10^{-6} \sim 3.0 \times 10^{-6}$ & $0.5 \times 10^{-6}$ & 24 \\
\hline Poly(L-Ornithine)/GCE & $5.0 \times 10^{-8} \sim 9.0 \times 10^{-6}$ & $1.7 \times 10^{-8}$ & This work \\
\hline
\end{tabular}

\subsection{Reproducibility, stability and interference}

To estimate the reproducibility of the proposed sensor, seven successive CV scans in $1.0 \times 10^{-6} \mathrm{~mol} \mathrm{~L}^{-1}$ thiamethoxam solution were recorded and the relative standard deviation (RSD) was determined to be $2.90 \%$. For five parallel fabricated PLO/GCEs, the RSD was 3.58\% revealing a good reproducibility. 
Furthermore, after PLO/GCE was stored in natural conditions for 14 days, the current response was retained $95.4 \%$ of its initial peak current value, which indicated the sensor had a good stability.

The influence of various potentially interfering substances for determination of $1.0 \times 10^{-6} \mathrm{~mol} \mathrm{~L}^{-1}$ thiamethoxam was studied by LSV. The tolerance limit for foreign species was taken as the largest amount yielding a relative error $\leq 5 \%$ for the determination of thiamethoxam. The results indicated that 100 -fold of $\mathrm{Al}^{3+}, \mathrm{SO}_{4}{ }^{2-}, \mathrm{Zn}^{2+}, \mathrm{NO}_{3}{ }^{-}, \mathrm{Ca}^{2+}, \mathrm{Mg}^{2+}, 50$-fold of citric acid, $\mathrm{AA}$, quinclorac, pymetrozine and 10fold UA had almost no influence on the determination(as shown in Fig. 9). This proved clearly the reasonable selectivity of the proposed method.

\subsection{Analysis of practical samples}

To evaluate the practical applicability of the proposed method, one commercially available insecticide was employed to determine the thiamethoxam content. The marked content of thiamethoxam in the insecticide was $30 \%$. The sample was treated simply by dissolving $116.68 \mathrm{mg}$ insecticide in $100 \mathrm{~mL}$ distilled water and then pipetting $10 \mu \mathrm{L}$ of this sample solution into $10 \mathrm{~mL} 0.1 \mathrm{~mol} \mathrm{~L}^{-1}$ PBS solution $(\mathrm{pH}$ 7.0), which was used as determination solution. Three parallel samples were analyzed with RSD of $1.90 \%$ and the detected content of thiamethoxam in practical sample was $29.88 \%$ (Table 2.). After determining the content of thiamethoxam, some standard thiamethoxam was added in the three samples respectively and the total content of thiamethoxam were determined again to calculate the recovery. As a consequence, the recovery obtained was $96.51 \%, 97.73 \%$ and $98.35 \%$ respectively (Table 3.). These results demonstrated the method's efficiency and applicability.

Table 2

The detected content of thiamethoxam in real sample.

\begin{tabular}{|llll|}
\hline Determination values/\% & Average determination value/\% & Declared content/\% & R.S.D/\% \\
\hline 29.26 & 29.88 & 30 & 1.90 \\
30.64 & & & \\
29.75 & & & \\
\hline
\end{tabular}


Table 3

The percentage of recovery for thiamethoxam in real sample.

\begin{tabular}{|lllll|}
\hline \begin{tabular}{|l} 
Original found \\
$\left(\mu \mathrm{mol} \mathrm{L}^{-1}\right)$
\end{tabular} & $\begin{array}{l}\text { Standard added } \\
\left(\mu \mathrm{mol} \mathrm{L}^{-1}\right)\end{array}$ & $\begin{array}{l}\text { Total found } \\
\left(\mu \mathrm{mol} \mathrm{L}^{-1}\right)\end{array}$ & $\begin{array}{l}\text { Recovery } \\
(\%)\end{array}$ & $\begin{array}{l}\text { R.S.D } \\
(\%)\end{array}$ \\
\hline 1.1925 & & 2.2719 & 96.51 & 3.62 \\
\hline & 1.0 & 3.1201 & 97.73 & 2.27 \\
\hline 3.0 & 4.2630 & 98.35 & 1.68 \\
\hline
\end{tabular}

\section{Conclusion}

In conclusion, an environmental-friendly and sensitive electrochemical method for determination of the thiamethoxam was developed using PLO/GCE as the voltammetric sensor. The electrochemical behaviors of thiamethoxam on the PLO/GCE were studied in detail. The sensor exhibited a low detection limit of $1.7 \times 10^{-8} \mathrm{~mol} \mathrm{~L}^{-1}(\mathrm{~S} / \mathrm{N}=3)$ and a wide linear detection range from $5.0 \times 10^{-8}$ to $9.0 \times 10^{-6} \mathrm{~mol} \mathrm{~L}^{-1}$ by LSV with excellent reproducibility and long-term stability. In addition, satisfactory results from the test in real samples had demonstrated the reliability of proposed method.

\section{Declarations}

\section{Acknowledgements}

This work was supported by the National Natural Science Foundation of China (Grant no. U1504216; 22176179)

\section{References}

1. A. Adachi, T. Okano, J. Health Sci. 52, 320 (2006)

2. W.L. Heinrichs, R.J. Gellert, Science. 173, 642 (1971)

3. J. Fitzgerald, Crop Prot. 24, 801 (2004)

4. A.S. Huseth, R.L. Groves, Plos One. 9, e97081 (2014)

5. S.P. Li, X.H. Cao, L.J. Liu, X.L. Ma, Deasalin Water Treat. 53, 3018 (2015)

6. E. Watanabe, T. Iwafune, K. Baba, Y. Kobara, Food Anal. Methods 9, 245 (2015)

7. P. Fidente, S. Seccia, F. Vanni, P. Morrica, J. Chromatogr. A 1094, 175 (2005) 
8. R. Irina, S. Ingrid, G.W. Daniel, R.H. Monika, G. Adrian, K. Jens, S. Arnaud, B. Thomas, J. Georg, BMC Cancer. 10, 242 (2010)

9. N. Ajermoun, S. Aghris, A. Farahi, S. Lahrich, S. Saqrane, M. Bakasse, M.A. Mhammedi, J. Electrochem. Soc. 167, 136507 (2020)

10. J. Ganesamurthi, M. Keerthi, S.M. Chen, R. Shanmugam, Ecotox Environ. Safe 189, 110035 (2020)

11. X.C. Zhai, H. Zhang, M. Zhang, X. Yang, C. Gu, G.P. Zhou, H.T. Zhao, Z.Y. Wang, A.J. Dong, J. Wang, Environ. Toxicol. Chem. 36, 1991 (2017)

12. Y.J. Wu, Z.K. Li, D.Y. Han, Q.P. Duan, F. Wang, J. Electrochem. Soc. 168, 126506 (2021)

13. J.D. Qiu, P.F. Hu, R.P. Liang, Anal. Sci. 23, 1409 (2007)

14. S. Gulsen, Y. Selehattin, Russ J. Electrochem. 51, 862 (2015)

15. C.Y. Qin, Y. Gao, W. Wen, X.H. Zhang, S.F. Wang, Biosens. Bioelectron. 79, 522 (2016)

16. Y.F. Li, L.N. Zou, G. Song, K.J. Li, B.X. Ye, J. Electroanal. Chem. 709, 1 (2013)

17. Q. Cao, H. Zhao, Y. Yang, Y.J. He, N. Ding, J. Wang, Biosens. Bioelectron. 26, 3469 (2011)

18. S. Fukuyama, H. Mihara, R. Miyake, M. Ueda, N. Esaki, T. Kurihara, J. Biosci. Bioeng. 117, 551 (2014)

19. E. Laviron, J. Electroanal. Chem. 101, 19 (1979)

20. F.C. Anson, Anal. Chem. 36, 932 (1964)

21. D. Nematollahi, H. Shayani-Jam, M. Alimoradi, S. Niroomand, Electrochim. Acta 54, 7407 (2009)

22. N. Ajermoun, A. Farahi, S. Lahrich, M. Bakasse, S. Saqrane, M.A. El Mhammedi, J. Sci. Food Agr 99, 4407 (2019)

23. S.X. Chen, L.J. Li, Y.P. Wen, G.Y. Yang, G.B. Liu, Y.F. Yi, Q.Y. Shang, X.X. Yang, S. Cai, Int. J. Electrochem. Sci. 14, 10848 (2019)

24. S.H. Peng, A.Q. Wang, Y.Y. Lian, X. Zhang, B. Zeng, Q.L. Chen, H.M. Yang, J.L. Li, L.M. Li, J.G. Dan, J.J. Liao, S.H. Zhou, Plos. One. 16, e0258508 (2021)

\section{Scheme}

Schemes 1-3 are available in the Supplementary Files section.

\section{Figures}




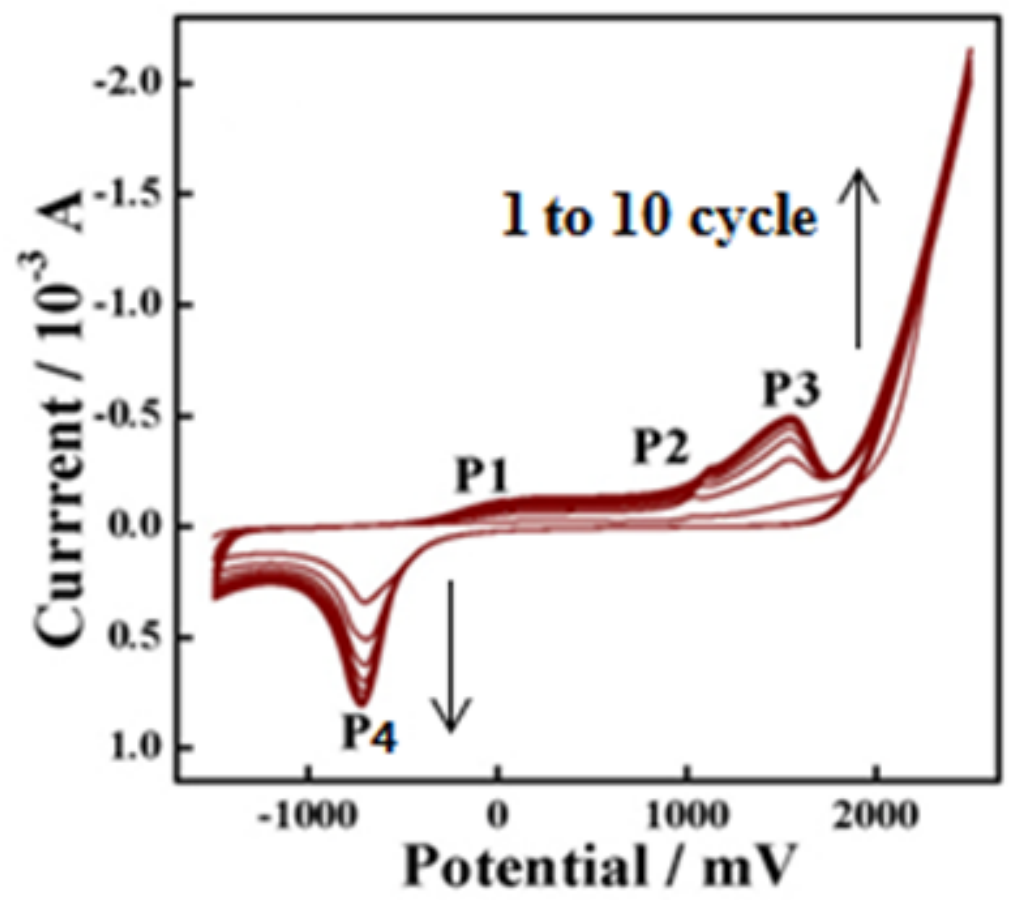

Figure 1

The voltammograms of poly(L-Ornithine) at GCE surface.

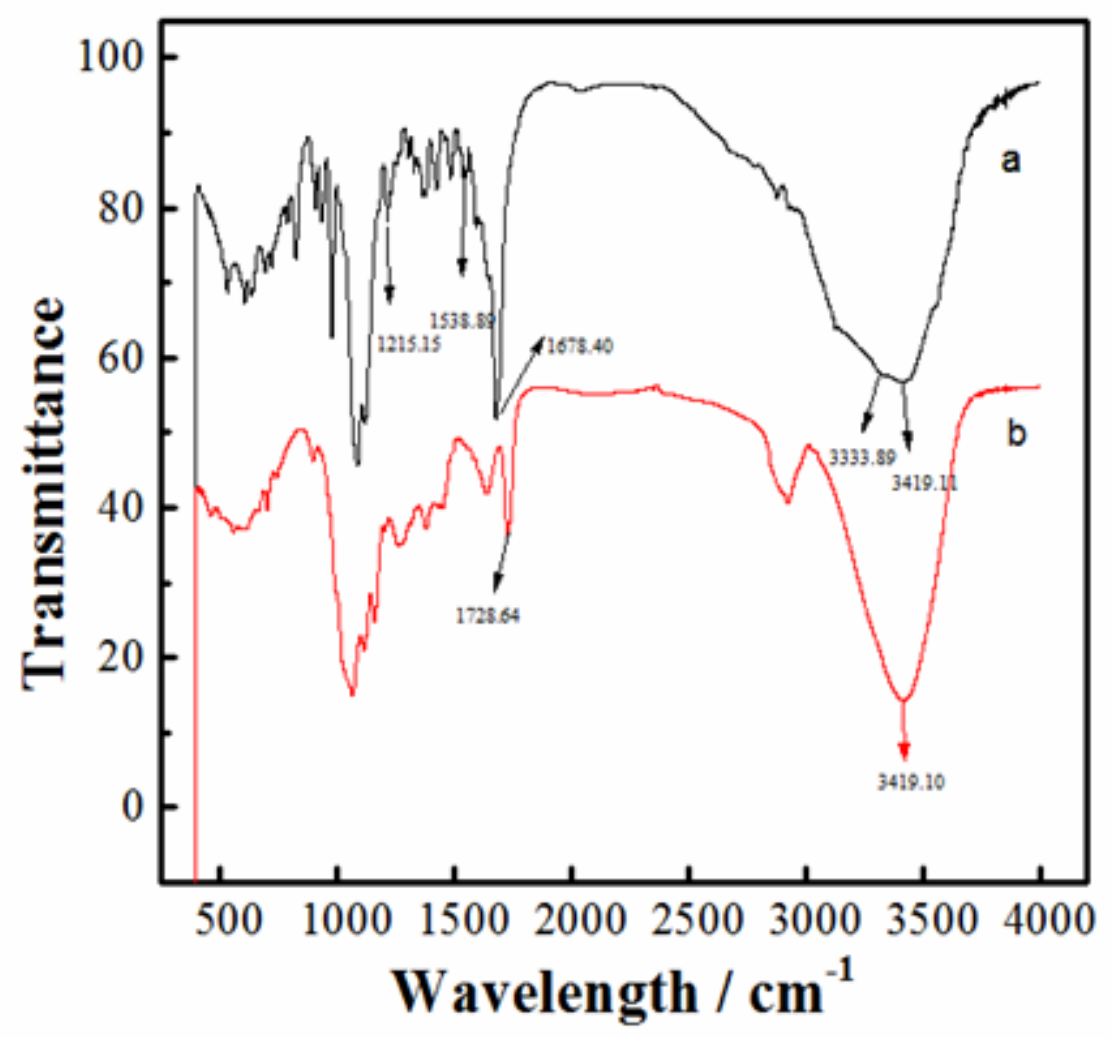

Figure 2 
The FT-IR spectra of L-Ornithine (a) and poly(L-Ornithine) (b).
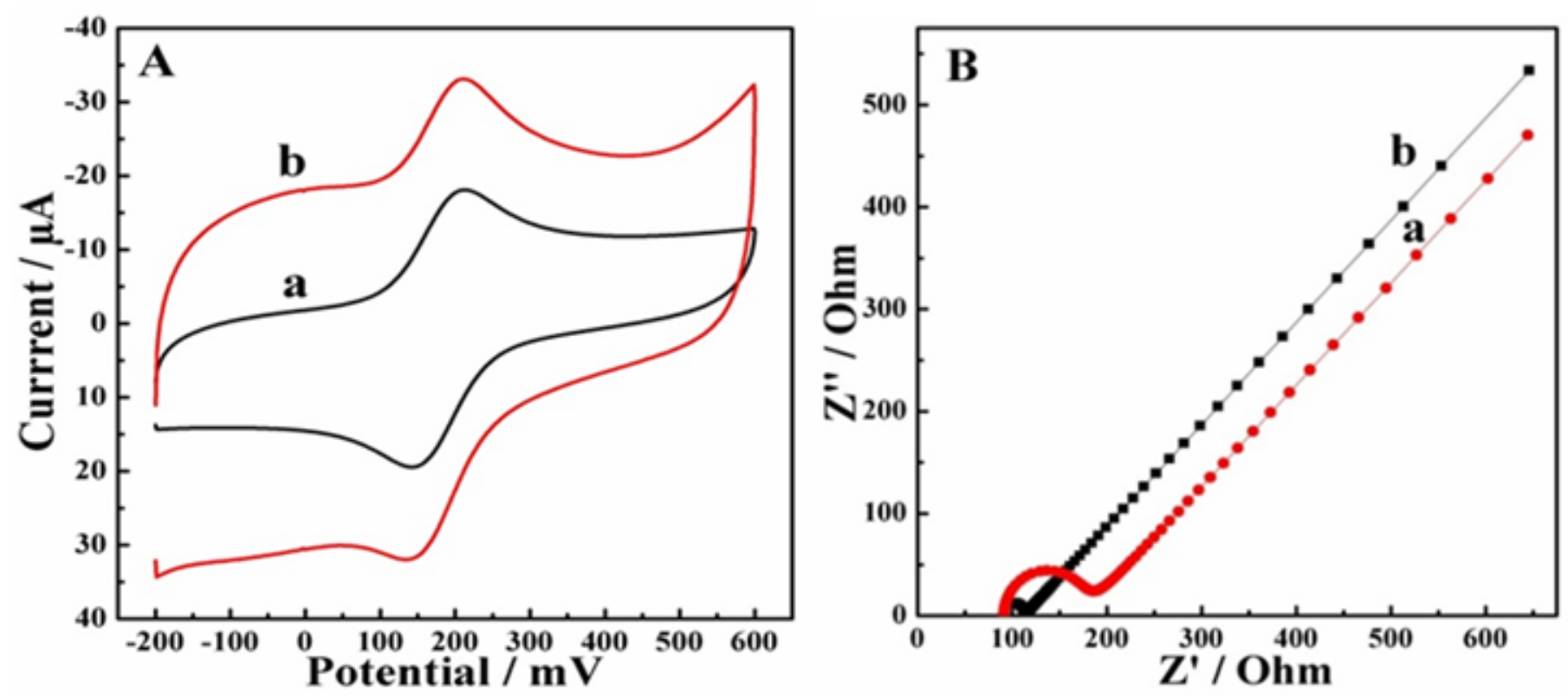

Figure 3

(A) Cyclic voltammograms of $\left[\mathrm{Fe}(\mathrm{CN})_{6}\right]^{3-/ 4-}\left(1.0 \times 10^{-3} \mathrm{~mol} \mathrm{~L}^{-1}\right.$ containing $\left.0.1 \mathrm{~mol} \mathrm{~L}^{-1} \mathrm{KCl}\right)$ at bare $\mathrm{GCE}(\mathrm{a})$, PLO/GCE (b); Scan rate: $100 \mathrm{mV} \mathrm{s}^{-1}$. (B) The Nyquist plots of EIS at bare GCE (a), PLO/GCE (b).

Supporting electrolyte: $5 \times 10^{-3} \mathrm{~mol} \mathrm{~L}^{-1}\left[\mathrm{Fe}(\mathrm{CN})_{6}\right]^{3-/ 4-}(1: 1)$ with $0.1 \mathrm{~mol} \mathrm{~L}^{-1} \mathrm{KCl}$ solution; Working potential: $0.285 \mathrm{~V}$; Frequency: $1 \mathrm{M} \mathrm{Hz}$ to $0.01 \mathrm{~Hz}$. 


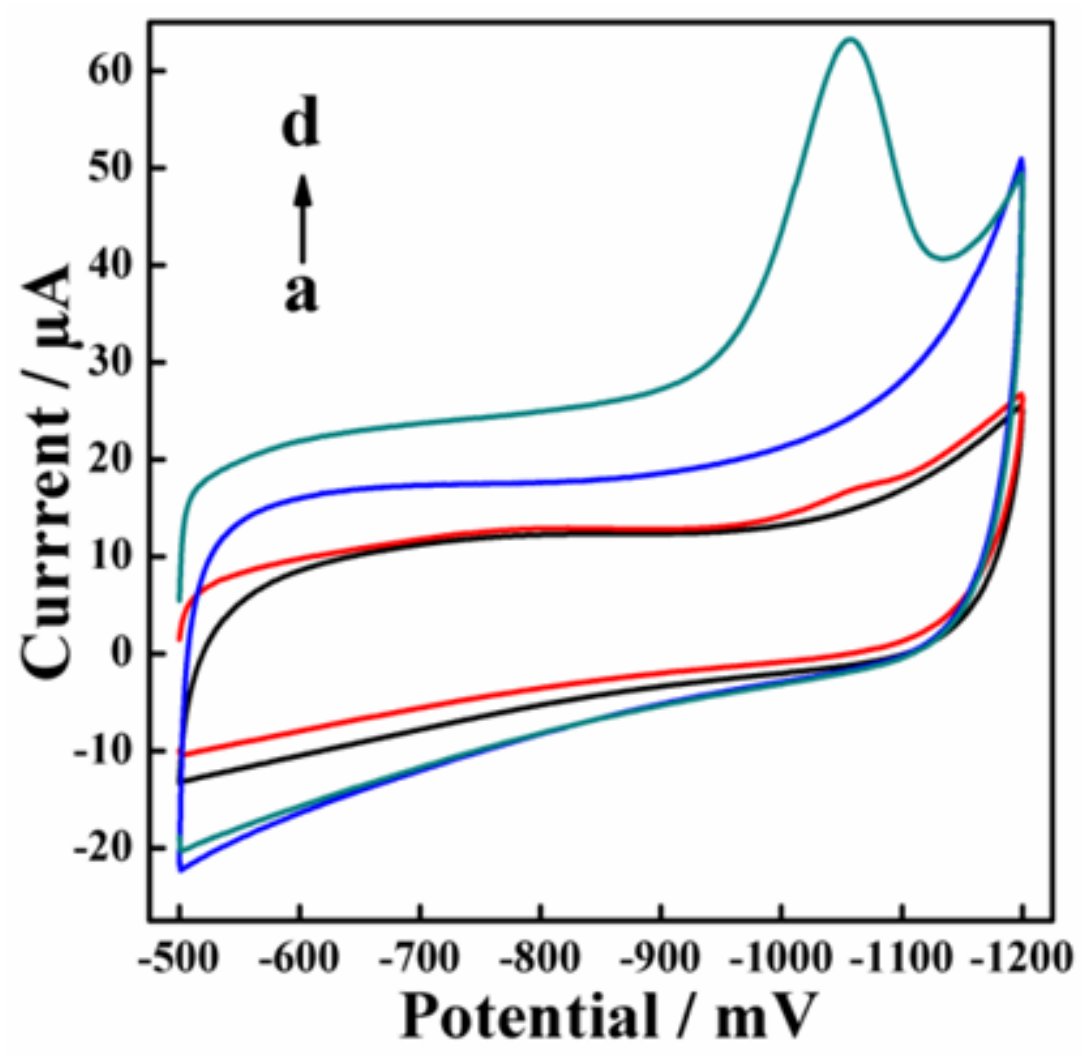

Figure 4

Cyclic voltammograms of thiamethoxam $\left(5.0 \times 10^{-5} \mathrm{~mol} \mathrm{~L}^{-1}\right)$ at bare GCE (b) and PLO/GCE (d). Cyclic voltammograms of Bare GCE (a) and PLO/GCE (c) in blank solution. (0.1 mol L-1 PBS 7.0, Scan rate: 100 $\mathrm{mV} \mathrm{s}^{-1}$ )
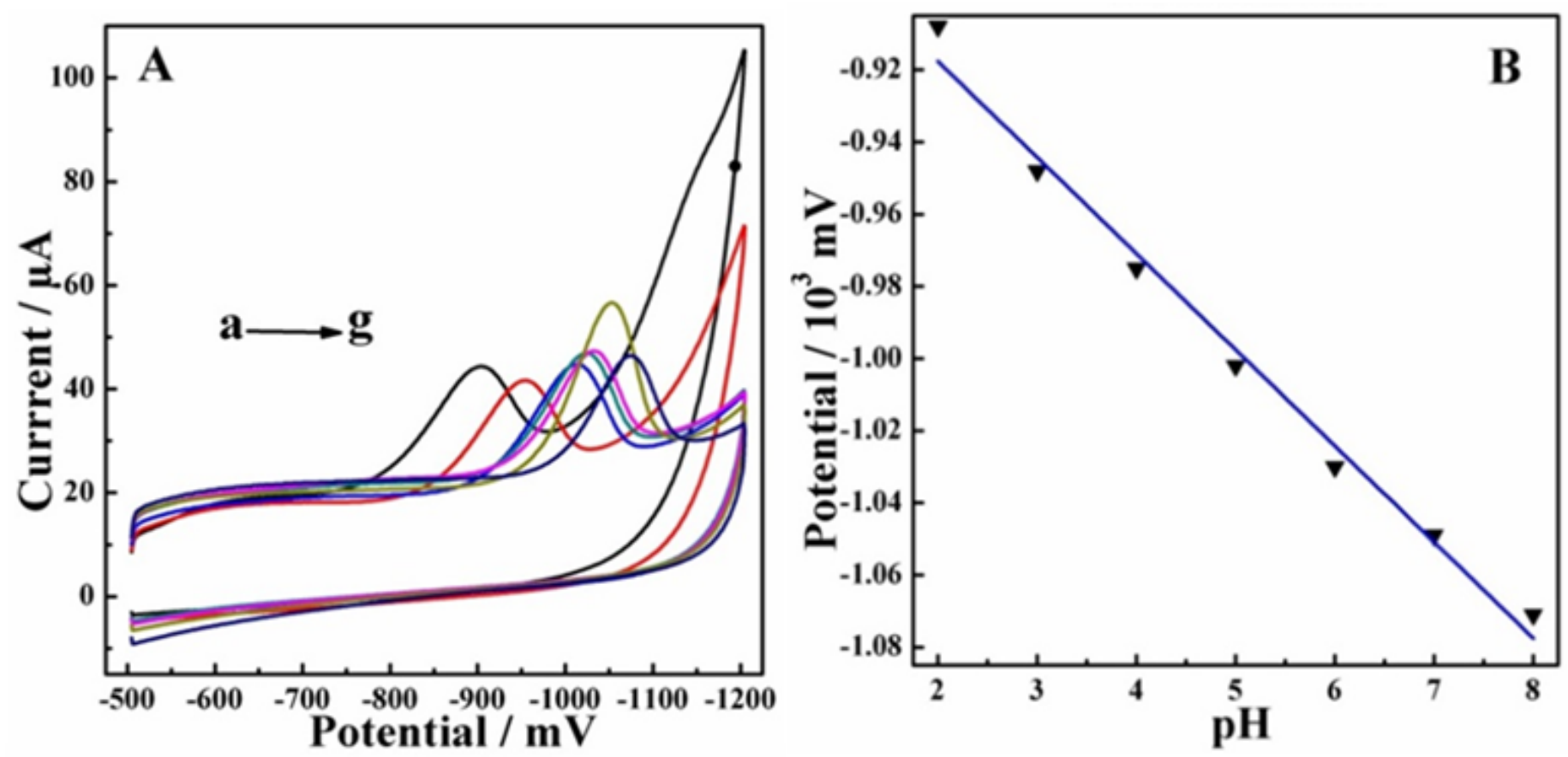
Figure 5

(A) The superimposed voltammogram of thiamethoxams $\left(5.0 \times 10^{-5} \mathrm{~mol} \mathrm{~L}^{-1}\right)$ at different pH of PBS (from curve a to g): 2.0, 3.0, 4.0, 5.0,6.0, 7.0, 8.0. Scan rate: $100 \mathrm{mV} \mathrm{s}^{-1}$. (B) The relationship between the peak potentials and $\mathrm{pH}$.
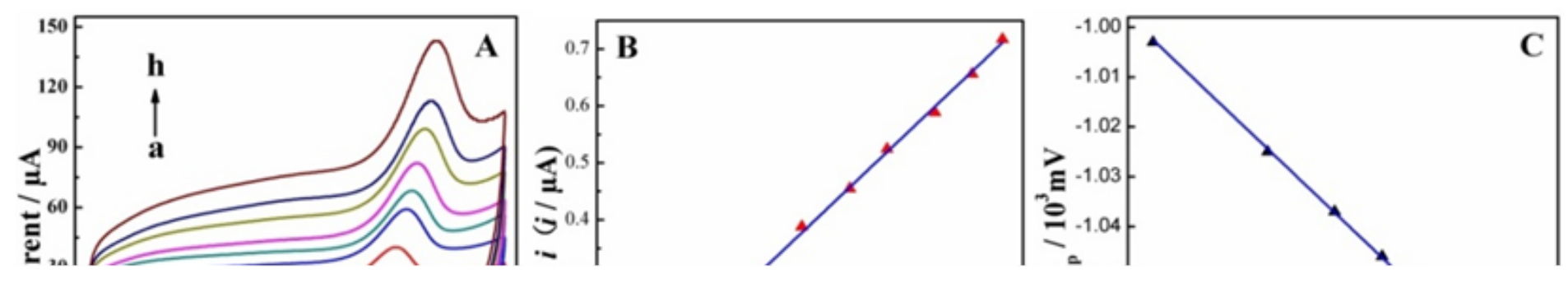

\section{Figure 6}

(A) The superimposed voltammogram of thiamethoxam $(5.0 \times 10-5 \mathrm{~mol}$ L- 1$)$ in $0.1 \mathrm{~mol} \mathrm{L-1}$ PBS solution (pH 7.0) with different scan rates (from a to h): $30,60,90,120,150,200,250$ and $300 \mathrm{mV} \mathrm{s}-1$. (B) The relationship of logarithm of $i$ vs. the logarithm of scan rate $(\log v)$. (C) The linear dependence of peak potential Ep against Inv.
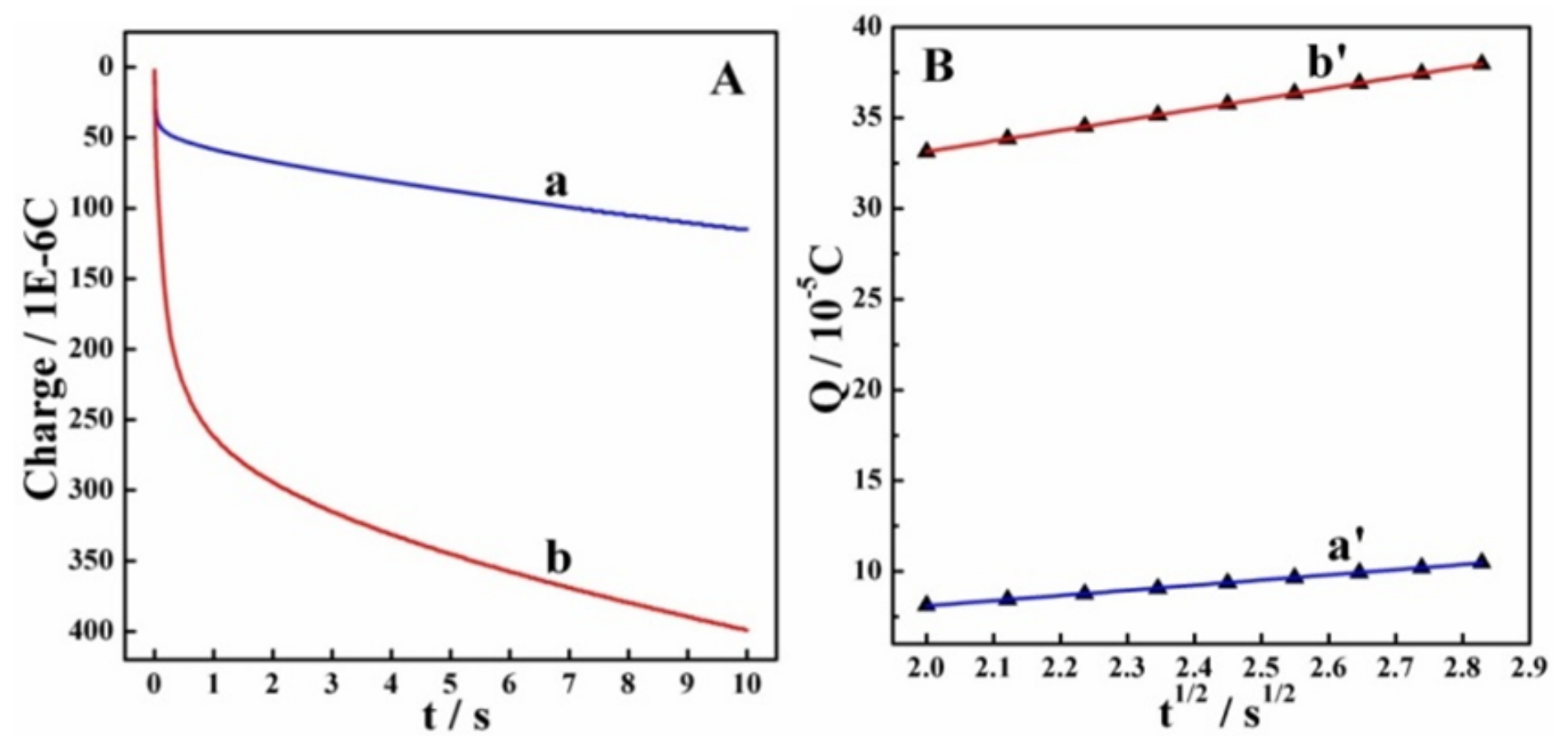

Figure 7 
(A) Chronocoulometric curves with absent (a) and present (b) of thiamethoxam $\left(1 \times 10^{-5} \mathrm{~mol} \mathrm{~L}^{-1}\right)$ in 0.1 mol L $\mathrm{L}^{-1}$ PBS 7.0. (B) The dependency of charge $\mathrm{Q}\left(10^{-5}\right) v s . \mathrm{t}^{1 / 2}$; corresponding data were derived from (A).
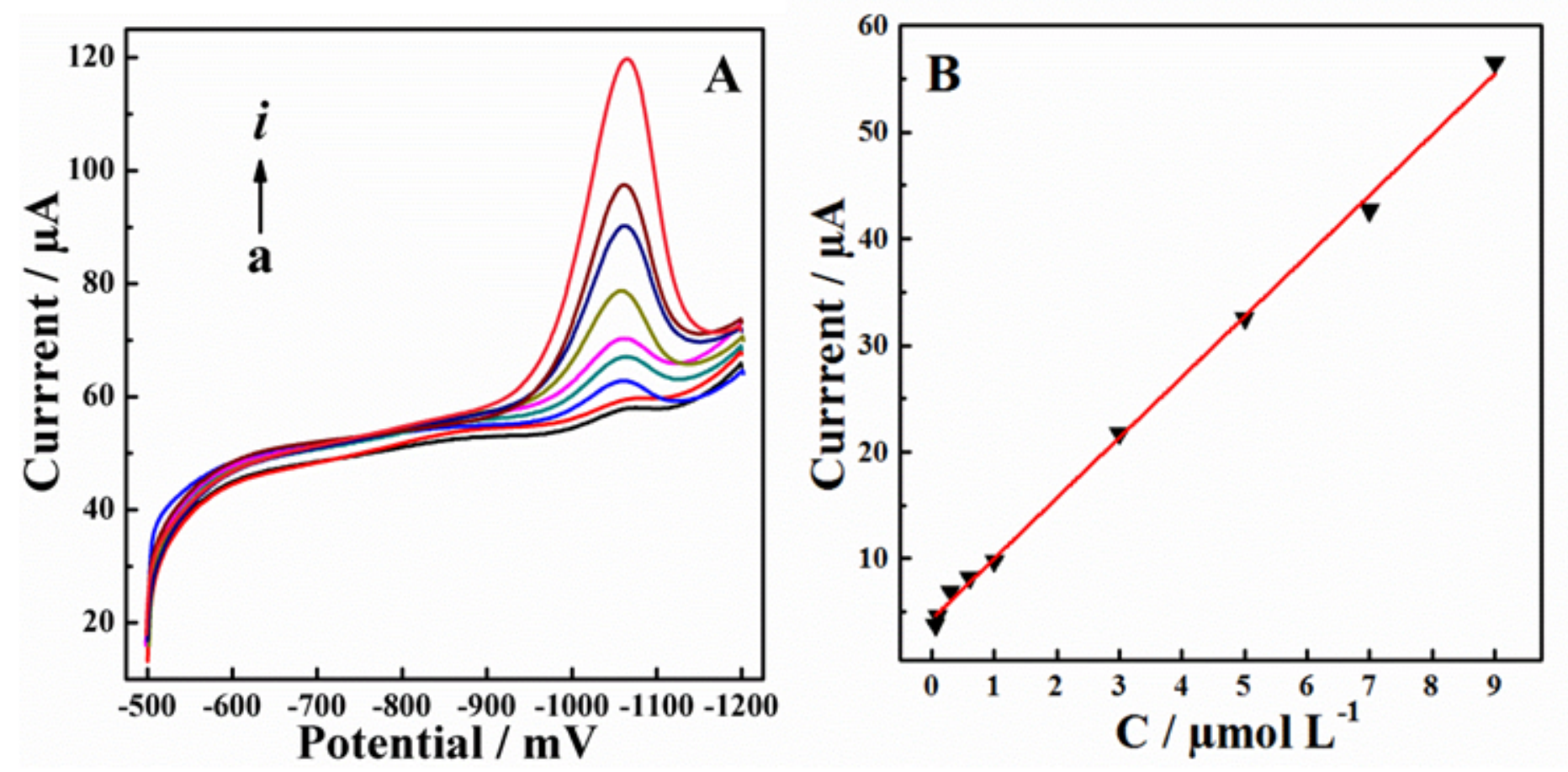

Figure 8

(A): The superimposed LSV curves of thiamethoxam with different concentrations $(a \rightarrow I): 5.0 \times 10^{-8}, 9.0 \times$ $10^{-8}, 3.0 \times 10^{-7}, 6.0 \times 10^{-7}, 1.0 \times 10^{-6}, 3.0 \times 10^{-6}, 5.0 \times 10^{-6}, 7.0 \times 10^{-6}, 9.0 \times 10^{-6} \mathrm{~mol} \mathrm{~L}^{-1}$. (B). The linear relationship of thiamethoxam concentrations versus peak currents. 


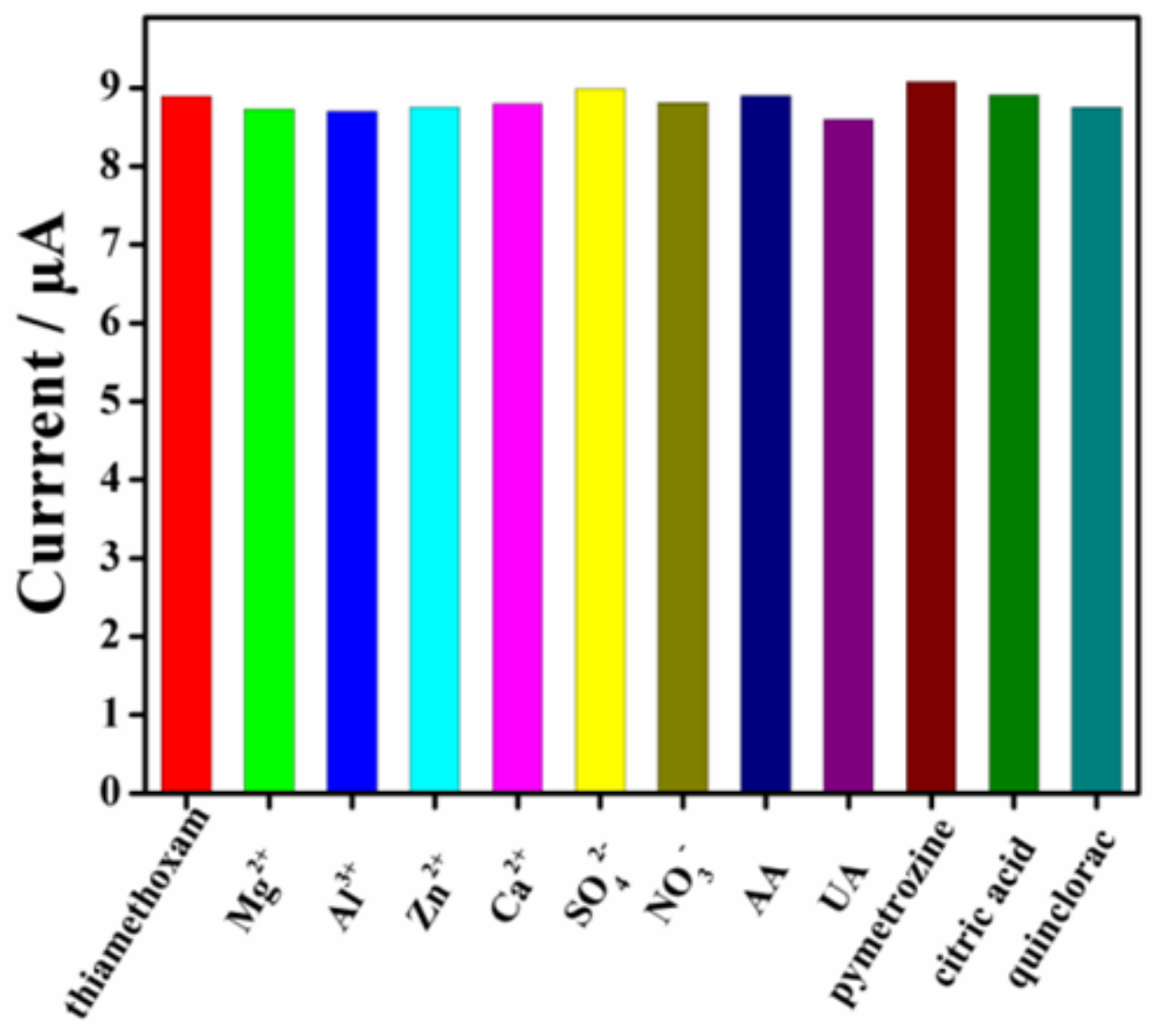

Figure 9

Column chart of the reduction peak current of $1 \times 10^{-6} \mathrm{~mol} \mathrm{~L}^{-1}$ thiamethoxam and co-exist with other metal ions or organic compounds.

\section{Supplementary Files}

This is a list of supplementary files associated with this preprint. Click to download.

- Scheme1.png

- Scheme2.png

- Scheme3.png 